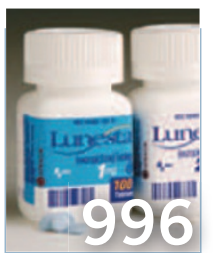

\author{
Rest easy: \\ New orexin-blocking \\ sleeping pills offer \\ safe shuteye
}

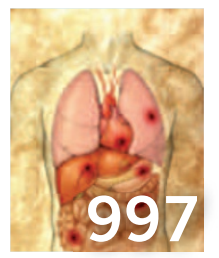

Shock therapy:

A special news

focus on sepsis

drug development

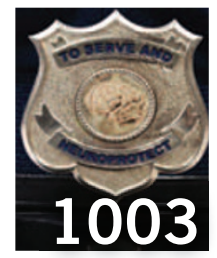

Stroke of genius:

The quest to

develop the first

neuroprotective stroke

drug

\title{
'Must-pass' FDA fee renewal jammed with sunscreen and more
}

Salmon and sunscreen may seem far removed from the world of cutting-edge drugs and medical devices. Yet both have been, at one time or another, part of the deal-making as the US Congress hashed out the details of the proposed Food and Drug Administration Safety and Innovation Act, currently making its way to the president's desk for final approval. The legislation will renew a version of the Prescription Drug User Fee Act (PDUFA), which requires makers of new therapies to pay fees to support swift completion of the FDA approval process.

On 18 June, the Senate and House of Representatives reconciled their versions of the bill, which policy analysts expect President Barack Obama to sign into law before the end of September, at the latest.

Researchers at the Tufts Center for the Study of Drug Development in Boston credit the law as cutting drug review times in half since its inception in 1992. The government needs to reauthorize a version of PDUFA every five years, and it is considered a must-pass measure because the FDA has become reliant on the money it generates, used to cover employee salaries. In 2010, for example, the more than $\$ 550$ million in user fees collected by the FDA covered $62 \%$ of the agency's costs for drug reviews.

The periodic reauthorization of PDUFA, however, gives special interests a chance to slip in tangentially related rules. "Knowing that this bill is going to pass, they try to put as much in it as they can," says Aaron Kesselheim, who studies health policy at the Brigham and Women's Hospital in Boston.

Indeed, a proposal by Republican Senator Lisa Murkowski of Alaska regarding genetically engineered salmon was introduced at one point, although it floundered and failed to make the final Senate version. It would have required an extensive study of the environmental and economic impacts of genetically modified salmon before it could be considered for FDA approval. Also off the table is a failed proposal to give drugs containing hydrocodone painkillers a more restrictive classification, which would have changed procedures for stocking and prescribing the medication.

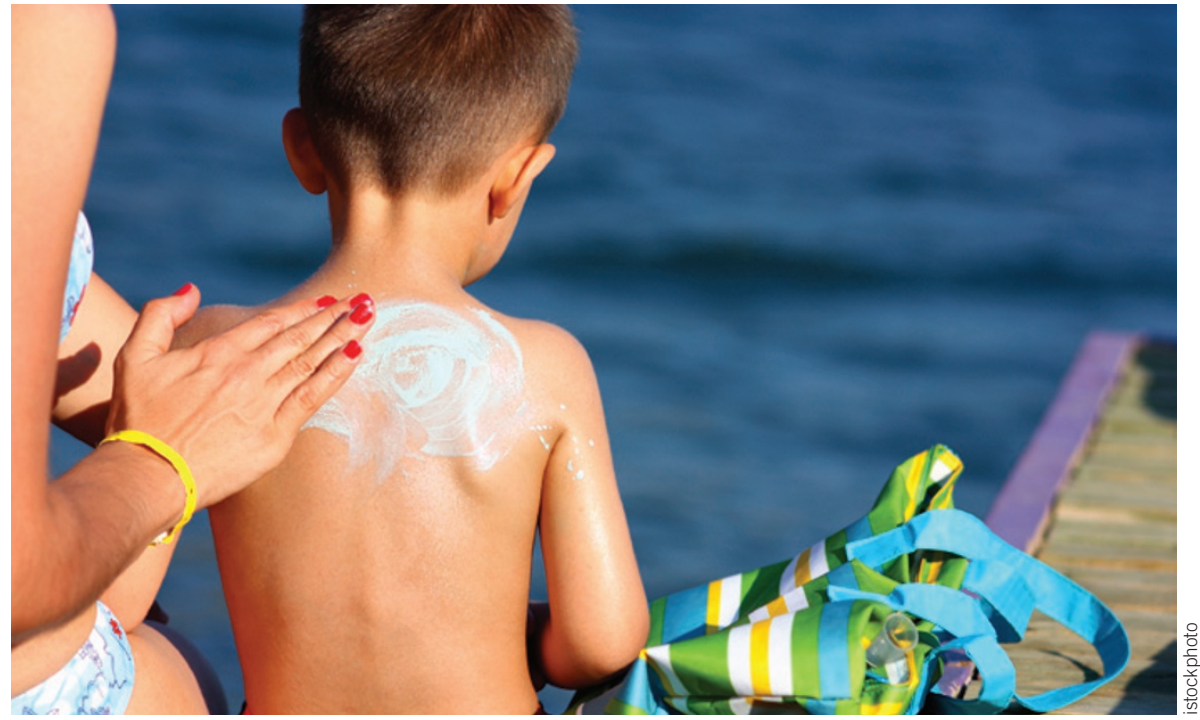

Layer it on: Legislators have tied rules for sunscreen and antibiotics to PDUFA.

Sunscreen remains in the latest version of the legislation, however. Provisional language in the PDUFA-renewing legislation extends by about six months the deadlines for compliance with a law passed last year that forbids sunscreen makers from using the words 'waterproof' or 'sweatproof' on their labeling

\section{Gaining additions}

Some people also see the legislation renewing the PDUFA framework as a possible Trojan horse for market protections for industry. As Nature Medicine went to press, the Food and Drug Administration Safety and Innovation Act included a provision designed to spur the development of new antibiotics, known as the Generating Antibiotic Incentives Now Act, or the GAIN Act (see Nat. Med. 17, 772, 2011). The GAIN legislation would ensure market exclusivity for new antibiotics for five years to reduce competition from other drugs.

The last time the PDUFA framework was renewed, in 2007, a rule was put in place requiring the FDA to slowly reduce the presence of experts with industry ties who serve on the agency's advisory panels. But meeting that requirement proved difficult, according to Celia Wexler, the Washington, DC representative of the nonpartisan Union of Concerned
Scientists, a Cambridge, Massachusetts-based organization that lobbies for evidence-based federal policy. "The FDA was nowhere near reaching that cap this year," she says. The new legislation headed to Obama would remove the cap on the number of experts with conflicts of interest.

The most recent versions of the PDUFA renewal also include rules that will add new responsibilities for the FDA, such as requiring the agency to regularly publish data on demographic subgroups included in studies of all products on which the FDA has oversight. "There hasn't been any transparency about who was included in studies conducted by industry," says Susan Wood, a women's health researcher at George Washington University in Washington, DC and former FDA assistant commissioner of women's health. Additionally, new language in the bill would compel the FDA to study and report drug shortages affecting life-supporting and life-sustaining medications.

There are, of course, updates that do apply to the fees themselves: one change will require makers of generic drugs and biosimilars to pay the same fees already paid by manufacturers of brand-name drugs.

Chase Scheinbaum 